\title{
KAFKA Y MARTÍNEZ ESTRADA
}

En diferentes ocasiones Ezequiel Martínez Estrada (Argentina, 1895-1964) expresó su admiración por Franz Kafka (Checoslovaquia, 1883-1924). La última vez que lo hizo fue para jactarse de haberlo imitado:

Confieso que le debo muchísimo - el haber pasado de una credulidad ingenua a una certeza fenomenológica de que las leyes del mundo del espíritu son las del laberinto y no las del teorema-, y creo que su influencia es evidente en mis obras de imaginación [...]. Quede hecha esta declaración de deuda ${ }^{1}$.

La influencia de Kafka en ese pasar de la idea de cosmos a la idea de caos quizá sea evidente en los ensayos - Martínez Estrada empezó a escribirlos en los años veintitantos cuando Kafka era un desconocido- pero no es evidente en los cuentos porque cuando escribió el primero ${ }^{2}$ ya había recibido el impacto de $\mathrm{Kafka}^{3}$. El

1 “Apocalipsis de Kafka", Israel y América Latina, 1960, núm. 98; recogido en En torno a Kafka y otros ensayos, Seix Barral, Barcelona, 1967.

2 "La inundación”, La Nación, Buenos Aires, 29 de junio de 1941.

${ }^{3}$ Attillo Dabini (La Nación, 2 de enero de 1972) recuerda que Martínez Estrada en carta del 14 de mayo de 1959 le confió que su mayor vocación era la de narrar y que lamentaba no haber podido realizarla: "y ya es tarde", agregó. En efecto, su producción cuentística fue tardía y relativamente escasa: sus Cuentos completos cupieron en un solo volumen de 467 páginas (Alianza, Madrid, 1975). Me referiré a sus libros con estas siglas: TC: Tres cuentos sin amor, 1956; MR: Marta Riquelme. Examen sin conciencia, 1956; SG: Sábado de Gloria, 1950; TOS: La tos y otros entretenimientos, 1957. He aquí una cronología de la composición de los cuentos basada en cartas y datos del autor: "La inundación", 1941 (TC); "Sábado de Gloria", 1944 (SG); "Viudez", 1945 (TC); "La cosecha", 1945-46 (TC); "Marta Riquelme" y "Examen sin conciencia", 1949 (MR); "Juan Florido, padre e hijo, minervistas", 1951-55 (SG); "La tos" y los doce "entretenimientos" que le siguen, 1957 (TOS). 
descubrimiento de Kafka y el despertar de la vocación narrativa de Martínez Estrada fueron simultáneos. No digo que entre ese descubrimiento y ese despertar haya una relación de causa a efecto sino que, en la producción cuentística de Martínez Estrada, no hay un "antes" y un "después" con respecto a la lectura de Kafka. La influencia de éste ha de notarse, pues, no en un cambio en la evolución de las ideas filosóficas, sino en la semejanza de situaciones, temas y argumentos entre los cuentos del maestro y los del discípulo.

La visión del mundo de Kafka es tan enigmática que nadie ha sabido definirla. Las interpretaciones de los críticos - teológicas, metafísicas, psicológicas, históricas, sociológicas, biográficas, estéticas - suelen desacreditarse unas a otras. ¿Cuál fue la de Martínez Estrada? Veamos unas pocas calas que ordeno cronológicamente para documentar cómo Martínez Estrada fue ampliando su conocimiento de Kafka. Más tarde se verá qué es lo que, de su personal interpretación de Kafka, le sirvió para escribir cuentos:

. . esa literatura [de realismo superficial] pierde inmensa parte de su prestigio cuando se entra al dédalo de novelas como El Castillo o El proceso, donde el centro del drama es desplazado otra vez a las tinieblas, como en los tiempos de la tragedia griega ${ }^{4}$.

La obra de Kafka, con sus inmensos valores literarios, queda engarzada en una concepción metafísica con tan preciso ajuste que el lector advierte que cada una de las piezas - novela o cuentoconecta su asunto con un argumento de dimensión universal. [...] Kafka nos trae a la superficie de la conciencia, a la delgada corteza gris de nuestro ser, y no por el camino de la reflexión, un mensaje místico de asombro y de estupor, en nadie antes tan vívido e inteligible ${ }^{5}$.

Lea usted ahora aquellos cuentos de Maupassant o de Chejov, y fijese en todo lo que no han contado, todo lo que dejaron a un lado como cosa de menor cuantía y dígame si se conforma con eso. Precisamente han omitido lo trágico, lo imponente, lo bello, lo cierto [...]. El cuentista realista recortaba, abstraía, podaba. Kafka es el primero que disuelve, amasa, mezcla ${ }^{6}$.

4 "El pájaro y la jaula", Correo literario, Buenos Aires, 1944, núm. 12; recogido en En torno a Kafka...

5 "Intento de señalar los bordes del mundo de Kafka", La Nación, 14 de mayo de 1944; recogido en En torno a Kafka. .

${ }^{6}$ Carta a Gregorio Schemes, 2 de junio de 1945, recogida en Carlos 
De singular relieve, como caso único en la historia de la literatura, el checoeslovaco Franz Kafka trajo el mensaje de prevenirnos de que vivimos en un mundo que nos es absolutamente desconocido, con seres absolutamente incomprensibles y regido por leyes caprichosas (a nuestro entender) absolutamente distintas a las de la física?.

Todos sus representantes están al servicio de potestades incógnitas, como en "La Muralla China" o en El Castillo de Kafka aquellos seres de un imperio de miles de millones de habitantes y de millones de kilómetros cuadrados están al servicio de un emperador arcaico, lejano, ya inexistente, que impartió sus órdenes decenas de siglos atrás ${ }^{8}$.

El mundo de Kafka no es fantástico sino con respecto al realismo ingenuo que acepta un orden fundado en Dios, en la razón o en el lógico acontecer de los hechos históricos. El "mundo del primitivo" se le asemeja funcionalmente más. [.. . ] Un mundo mágico, en fin, que difiere del cosmos urbano del teólogo, del filósofo y del sociólogo. [...] Kafka es también un hombre primitivo, un hombre para quien las leyes de la causalidad no existen. [...] El mundo de Kafka, en resumen, es el mundo real ${ }^{9}$.

Yo también, durante muchos años, creí que la realidad se me ofrecía candorosamente a los sentidos. [.. . ] Pero un día, leyendo una novela de Franz Kafka [El proceso], percibí que la manera de tratar él la realidad como algo declaradamente absurdo estaba más cerca de la realidad que la de otros autores, Zola por ejemplo ${ }^{10}$.

En cierto sentido Kafka es portador de un mensaje de raza y némesis que podría de inmediato atribuir al "inconsciente ancestral colectivo", en lenguaje de Jung. Sus personajes, sus temas y las vicisitudes o tribulaciones que integran regularmente el argumento y la tesis encajan perfectamente en el concepto de mito como se lo ha estudiado recientemente en las afloraciones del yo profun-

AdAM, Bibliografía y documentos de E.M.E., Universidad Nacional de La Plata, 1968.

${ }^{7}$ Panorama de las literaturas, Claridad, Buenos Aires, 1946.

${ }^{8}$ Muerte y transfiguración de Martín Fierro, FCE, México, 1948, t. 2, pp. 199, 279 y 390 .

9 "Acepción literal del mito en Kafka", Babel, Santiago de Chile, 1950, núm. 53; recogido en En torno a Kafka...

10 "Lo real y el realismo", CuA, 1958, núm. 100, 258-264; recogido en En torno a Kafka... 
do del estrato epitelial de la razón. El hecho de que esos personajes por lo regular no tengan nombre ni lo necesiten, que no se nos diga ni hay por qué saberlo cómo son, de dónde proceden ni dónde están, colocándolos como piezas móviles e intercambiables de un gran azar que configura una realidad, lo demuestra ${ }^{11}$.

Distingamos entre la totalidad de valores que Martínez Estrada celebraba en Kafka y la parte mínima que escogió para enriquecer sus propios cuentos. Aun es posible que algunas situaciones aparentemente kafkianas procedan directamente de narradores que Kafka, a su vez, había aprovechado, como Poe, Gogol, Dickens, Dostoievsky et al. (Sin contar que a lo mejor Martínez Estrada sacaba esas situaciones, no de Kafka, ni de nadie, sino de su magín.)

\section{Situaciones semejantes entre KafKa y Martínez Estrada}

\section{La complicación infinita}

Kafka veía en el universo mera materia sin propósito y veía en sí mismo una vana complejidad mental. Negaba la existencia de un dios personal y afirmaba lo que para él era una evidencia: que la estupidez de este mundo humano es parte de una universal estupidez. El universo es un laberinto sin Ariadnas ni Teseos. Es un laberinto que se complica tanto en el espacio ("La madriguera', "Un mensaje imperial") cuanto en el tiempo ("La próxima ciudad", "El escudo de la ciudad"). Espacio-temporal es "La construcción de la Gran Muralla China', donde muros y siglos son infinitos. En el laberíntico universo de Kafka las cosas se multiplican y los hechos se postergan. En América, en El proceso y en El Castillo los protagonistas corren sin progresar, como en una pesadilla. Las almas también son laberínticas.

Martínez Estrada crea la ilusión dei laberinto mediante el doble procedimiento de descomponer un objeto complicado en simples elementos y en componer con varios objetos simples una figura complicada. Análisis y síntesis. Percepción de pormenores e invención de constelaciones. Átomos y moléculas. Células y tejidos. En Marta Riquelme la casa de la Magnolia -orgánica, viviente como el Castillo de Kafka - es una finca colonial a la que 
se han adherido habitaciones, patios, tapias; su campo se lotea y así surge una ciudad ocupada por una profusa parentela. "Es el lugar - dice Marta- donde todos vivimos pero de donde no podemos salir". La descripción del conventillo en "Juan Florido, padre e hijo, minervistas", de la iglesia invadida en "La inundación", de los apartamentos en "La escalera", del hospital en "Examen sin conciencia" sugiere que las incoherencias en una parcela del mundo reflejan la gran incoherencia del mundo entero.

\section{El fracaso}

Kafka pobló sus ficciones con fracasados. Sus personajes ni saben ni quieren ni pueden vivir. Son solitarios. O ineptos. O neuróticos. En el mejor de los casos, víctimas del desorden universal. A veces el universo se les echa encima, como en El proceso: apenas el inocente José $\mathrm{K}$. despierta se ve arrestado por representantes de un poder ciego; es inútil que pida explicaciones; nunca le dirán de qué lo acusan; los tribunales que lo han condenado son inescrutables; al final, lo ejecutan. Otras veces los personajes se lanzan en busca de la llave del universo, como en El Castillo: el agrimensor $\mathrm{K}$. ha sido contratado para prestar servicios profesionales en la propiedad de un Conde pero jamás verá al propietario, jamás superará los obstáculos que le impiden, no digamos cumplir con su tarea, pero ni siquiera averiguar de qué tarea se trata.

Martínez Estrada también permite que sus personajes reciban golpes de una realidad antojadiza o que, si emprenden una acción, no puedan avanzar o tengan que retroceder. En "Examen sin conciencia" Cireneo Suárez va a visitar a un enfermo en el hospital y un remolino de equívocos se apodera de él y lo hunde en angustias y humillaciones. Así como a José K. una organización irresponsable lo ejecutó sin causa, a Cireneo Suárez un hospital trastornado por una revolución lo mete en el quirófano y allí lo operan sin necesidad. La reflexión final de Cireneo no puede ser más kafkiana:

de pronto se aclaró su cerebro. Comprendió con suma lucidez que nada de lo que había ocurrido era absurdo, sino perfectamente lógico y congruente con su destino. Toda su vida estaba tejida sobre una inflexible urdimbre, de la que precisamente lo acontecido esa mañana componía los hilos más resistentes y ocultos en que se sostenían todos los otros días de su vida... 
Más con el esquema de El Castillo (que es el inverso del esquema de El proceso) el protagonista de "Sábado de Gloria", Julio Nievas, tiene un plan: partir para Mar del Plata en uso de sus vacaciones. Pero ha estallado una revolución y las locuras del nuevo régimen y de la nueva burocracia no se lo permiten. También kafkianamente se da cuenta de que

estaba entrelazado por razones que le eran desconocidas; de que nada de lo que ocurría era cierto. Algo así como si hubiera sufrido un síncope y ahora, en los infiernos, comenzara su martirio con procedimientos que iban gradualmente aumentando y que llegarían, sin duda, a lo infinito e inimaginable.

\section{Jerarquias vacias}

Kafka planta a sus personajes en un orden engañoso. El engaño consiste en que se trata de un orden dentro del desorden. Hay poderes, autoridades, legisladores, pero no funcionan. En "El problema de nuestras leyes" se demuestra que esas leyes ocultas que los nobles han impuesto en verdad no existen sino en una vaga tradición. Los tribunales en $E l$ proceso no juzgan. El mensajero, en "Un mensaje imperial" - - extracto de "Construcción de la Gran Muralla China" - no logra salir del palacio y por tanto nunca llega a cumplir con su misión. El Conde en El Castillo no aparece nunca, y su delegado Klamm es una eminencia demasiado gris.

Martínez Estrada traduce los inoperantes funcionarios de Kafka a términos de burocracia argentina. El escalafón de director general, director interino, jefe, segundo jefe, encargado, subencargado, ordenanza en "Sábado de Gloria" recuerda el escalafón de "Construcción de la Gran Muralla China" con su Emperador, Directores, arquitectos, albañiles, capataces y jornaleros. El Hospital, en "Examen sin conciencia", es una anarquía de médicos, estudiantes, enfermeras, políticos y empleados tan incapaces y corrompidos como los miembros de las cortes de justicia en El proceso.

\section{El accidente inicial}

Kafka inicia sus narraciones con un incidente insólito o preternatural que desencadena una serie de desastres. Un hombre despierta transformado en insecto ("La metamorfosis") o en delin- 
cuente (El proceso). El deseo de mandar por correo una participación matrimonial a un amigo termina en suicidio ("El veredicto").

Martínez Estrada inicia sus narraciones con un hecho que produce efectos desproporcionados. La rotura de la máquina cosechadora, en "La cosecha", acaba por romper el ánimo del formidable Don Aparicio: después de padecer contratiempos y vejámenes se pone "a llorar entre sollozos". La vida conyugal de Adolfo Rauch cambia radicalmente desde que tose ("La tos"). La sequía en "Viudez" y el velatorio en "Juan Florido, padre e hijo, minervistas" se despliegan en un panorama, trágico uno, grotesco el otro.

\section{La exageración}

Kafka, aun en sus ficciones más realistas, o sea, en esas que describen una realidad ordinaria, exagera tanto los hechos que toda la realidad acaba por disolverse en sueño, en símbolo, en poema, en humorada, en absurdidad o en fantasía. Aparte sus ya mencionadas novelas recuérdense cuentos como "El artista del hambre" y "Primera pena" (más conocido como "El artista del trapecio"). Martínez Estrada se mantiene más realista que inventivo pero con sus exageraciones consigue un clima de inverosimilitud. En el extremo más poético, "La inundación"; en el extremo más truculento, uno de sus mejores cuentos: "Juan Florido, padre e hijo, minervistas'.

\section{El anonimato}

Kafka se divertía en jugar con los nombres y apellidos de sus personajes, sea omitiéndolos, reduciéndolos a una letra o cargándolos de intenciones secretas. En el fondo esos juegos indican que Kafka pensaba en sus personajes, no como personas concretas, únicas, bien individualizadas, sino como anti-héroes anónimos, abstractos, colectivos.

Martínez Estrada, además de los nombres y apellidos normales, ofrece una nomenclatura traviesa y deformada ("Cruth" en vez de "Cruz", etc.). Al orgulloso agricultor de "La cosecha" en una oficina pública le reducen el nombre Don Aparicio al número 122. En "Juan Florido, padre e hijo, minervistas" el vecino de la habitación 135 cada semana se cambia de nombre siguiendo el orden del alfabeto, y así una semana le toca ser Anacleto, otra Braulio, otra Dámaso... 


\section{La ambigüedad}

Hasta ahora he anotado características de la obra de Kafka que pasaron a la de Martínez Estrada. Quisiera detenerme en una que pasó, sí, pero sólo por excepción, y es la característica de la ambigüedad.

Kafka fue siempre, desde el primer cuento hasta el último, un escritor ambiguo. Las palabras de un texto suyo no significan lo que dicen sino lo contrario y a veces ni siquiera lo contrario sino algo irrazonable o hermético. Muchos críticos, desorientados, buscan inútilmente las claves de enigmas que ellos creen ser alegorías. Kafka comprendió la naturaleza y límites de su conocimiento, descubrió dentro de su conciencia los desbarajustes del Yo y del No-Yo y se dedicó a exponer problemas y dudas. Pero no lo hizo con un discurso lógico. Debió de presentir que todo razonamiento cuando se prolonga demasiado acaba por enfermarse. Prefirió, pues, que sus reflexiones quedaran inconexas; y lo que sus inconexas reflexiones le dijeron fue que no vale la pena pensar sistemáticamente y por tanto es mejor mantenerse en una posición escéptica; y que como también el escepticismo puede endurecerse en sistema conviene escribir con un estilo ambiguo sobre situaciones ambiguas. Ejemplos: "Josefina la cantante o El Pueblo de Ratas" y "Un artista del hambre". En ambos cuentos el tema es la pretensión de los artistas a ser estimados socialmente. Pues bien: Kafka es inconsecuente, se contradice, nos deja en ayunas. En cambio Martínez Estrada, que tocó el mismo tema en "No me olvides", es terminante: duda sobre la sensibilidad artística de la sociedad pero no sobre los méritos del artista.

Martínez Estrada admitía que la mente humana es un teatro donde actúan, junto con la lógica, impulsos voluntariosos, subconscientes, emotivos, irracionales, fantasísticos. Pero él quería ver en la oscuridad, quería explicar lo inexplicable. Sus cuentos no se prestan, como los de Kafka, a que los críticos fabriquen falsas alegorías; el Cireneo de "Examen sin conciencia", como el Cireneo del Evangelio de San Mateo, XXVII, 32, lleva una cruz, pero esa cruz de tira emplástica que venda la herida en su cabeza es un chiste, no un símbolo teológico. No hay ambigüedad voluntaria en sus cuentos, ni siquiera en los menos realistas. La excepción fue "Marta Riquelme". Y porque "Marta Riquelme" es un cuento ambiguo reconocemos en él las huellas de Kafka. Es un cuento dentro de un cuento en forma de prólogo. Un tal "Martínez Estrada" tiene que prologar la imposible edición de unas escandalosas Memorias escri- 
tas por alguien que no sabe escribir. Las ha escrito - no se sabe ni dónde ni cuándo- una tal "Marta Riquelme", tocaya de la mujer que en un cuento de W. H. Hudson se transforma en pájaro. El manuscrito, indescifrable y quizá apócrifo, se ha extraviado (o quizá nunca existió). La autora, si existe, es mística y obscena, sincera y mentirosa, satánica e inocente, infantil y senil, y las frases de sus páginas dispersas, cuando se entienden, cambian de sentido según el contexto en que se las intercale.

\section{Características kafkianas Que no se hallan en Martínez Estrada}

a) Cuentos con animales como protagonistas (rata en "Josefina la cantante o El Pueblo de Ratas"; mono en "Informe para una Academia" ; insecto en "La metamorfosis"; caballo en "El nuevo abogado"; perro en "Investigaciones de un perro"; animales fantásticos en "La madriguera" y "Una preocupación para el casero").

b) Cuentos fantásticos, esto es, con irrupción de un factor sobrenatural en una acción natural ("La metamorfosis", " $E 1$ jinete en un balde", "El cazador Gracchus").

c) Cuentos de ambiente onírico con sueños, pesadillas, duermevelas que no están presentados como fenómenos psicológicos sino como magia ("Un doctor rural", "El veredicto"). En cambio Martínez Estrada echó a perder su cuento "La explosión" porque, cediendo a un escrúpulo realista, lo explicó como pesadilla: "Al despertarse Blas Brass comprendió...'”.

\section{Diferencias personales entre Martínez Estrada y Kafka}

Kafka era nihilista, pesimista, masoquista. Se complacía en atormentarse con exagerados sentimientos de culpa. El hombre, para él, era siempre culpable de una culpa metafísica. El mito judío del pecado original penetró en muchos de sus cuentos. Por ejemplo, en "El veredicto" y, sobre todo, en el más cruel de todos, "La colonia penitenciaria", tan cruel que el masoquismo recrudece en sadismo. En este cuento vemos un mundo sin valores donde la debilidad humana es castigada por una máquina infernal. Hay un momento en que Kafka juzga su propia vida desde fuera, en relación con su familia, y desea morir. La vida es una porquería. Repugnado, escribe el autobiográfico relato "La metamor- 
fosis", donde Gregor Samsa se transforma en un insecto y al final muere abandonado por sus familiares.

Martínez Estrada, lejos de ser masoquista, era de los que se quejan porque no quieren sufrir. Se creía importante y echaba la culpa de sus sufrimientos a los demás. Estaba amargado, resentido, pero tenía esperanzas de mejorar el mundo y de mejorarse. Era un luchador, un polemista, con una retórica aparentemente pesimista pero de conducta política insuflada de optimismo: creía, patrióticamente, en la posibilidad de levantar en nuestra tierra la utopía de una sociedad justa, libre y culta. Los males que describió son corregibles.

\section{Males universales EN TIERRA ARGENTINA}

Kafka describe con detalles muy reales su mundo irreal. Es la técnica de los narradores de sueños, embustes, ucronías y utopías. Presenta a sus personajes como víctimas del caos. En esa tiniebla es natural que sus cuentos no tengan color local.

Martínez Estrada también narra con procedimientos minuciosamente realistas. Aunque cree, como Kafka, que la vida es difícil en un universo azaroso, baja la vista a lo inmediato y presenta a sus personajes como víctimas de la desorganización social y política de la Argentina. Revoluciones, cuartelazos, dictaduras, caudillajes, burocracias viciosas, masas ignorantes y costumbres bárbaras son las furias que hacen sufrir a los agonistas de "Viudez", "La cosecha”, " Sábado de Gloria", "Examen sin conciencia", "No me olvides", "En tránsito". Estos cuentos vienen a ilustrar, a todo color, sus ensayos sociológicos sobre nuestro país. Atención a las fechas. Digo que los cuentos podrían adornar, como gráficas ilustraciones, el texto, no tanto de los ensayos de $R a$ diografía de la pampa (1933) y La cabeza de Goliath (1940) cuanto de los escritos durante las dictaduras militares de 1943 en adelante, incluyendo, naturalmente, la del coronel Perón. 